\title{
Development and Evaluation of a Mobile Decision Support System for Hypertension Management in the Primary Care Setting in Brazil: Mixed-Methods Field Study on Usability, Feasibility, and Utility
}

Daniel Vitório Silveira ${ }^{1,2,3}$, MD; Milena Soriano Marcolino ${ }^{1,2,3}, \mathrm{MSc}, \mathrm{MD}, \mathrm{PhD}$; Elaine Leandro Machado $^{2}, \mathrm{MSc}^{2}$ $\mathrm{PhD}$; Camila Gonçalves Ferreira ${ }^{2}$, BSN; Maria Beatriz Moreira Alkmim ${ }^{1,2,3}$, MSc, MD; Elmiro Santos Resende ${ }^{2,4}$, MSc, MD, PhD; Bárbara Couto Carvalho², MD; André Pires Antunes ${ }^{2,5}$, MSc, MD; Antonio Luiz Pinho Ribeiro ${ }^{1}$, $\mathrm{MD}, \mathrm{PhD}$

\footnotetext{
${ }^{1}$ Telehealth Center, Hospital das Clínicas, Universidade Federal de Minas Gerais, Belo Horizonte, Brazil

${ }^{2}$ Post-Graduate Program in Infectious Diseases and Tropical Medicine, Faculdade de Medicina, Universidade Federal de Minas Gerais, Belo Horizonte, Brazil

${ }^{3}$ Telehealth Network of Minas Gerais, Belo Horizonte, Brazil

${ }^{4}$ Medical School, Universidade Federal de Uberlândia, Uberlândia, Brazil

${ }^{5}$ Medical School, Universidade Estadual de Montes Claros, Montes Claros, Brazil
}

\section{Corresponding Author:}

Antonio Luiz Pinho Ribeiro, MD, PhD

Telehealth Center

Hospital das Clínicas

Universidade Federal de Minas Gerais

Av. Professor Alfredo Balena, 110, Sl 107

Santa Efige^nia, 30.130-100

Belo Horizonte,

Brazil

Phone: 553134099201

Fax: 553134099234

Email: tom@hc.ufmg.br

\section{Abstract}

Background: Despite being an important cardiovascular risk factor, hypertension has low control levels worldwide. Computerized clinical decision support systems (CDSSs) might be effective in reducing blood pressure with a potential impact in reducing cardiovascular risk.

Objective: The goal of the research was to evaluate the feasibility, usability, and utility of a CDSS, TeleHAS (tele-hipertensão arterial sistêmica, or arterial hypertension system), in the care of patients with hypertension in the context of a primary care setting in a middle-income country.

Methods: The TeleHAS app consists of a platform integrating clinical and laboratory data on a particular patient, from which it performs cardiovascular risk calculation and provides evidence-based recommendations derived from Brazilian and international guidelines for the management of hypertension and cardiovascular risk. Ten family physicians from different primary care units in the city of Montes Claros, Brazil, were randomly selected to use the CDSS for the care of hypertensive patients for 6 months. After 3 and 6 months, the feasibility, usability, and utility of the CDSS in the routine care of the health team was evaluated through a standardized questionnaire and semistructured interviews.

Results: Throughout the study, clinicians registered 535 patients with hypertension, at an average of 1.24 consultations per patient. Women accounted for $80 \%$ (8/10) of participant doctors, median age was 31.5 years (interquartile range 27 to 59 years). As for feasibility, $100 \%$ of medical users claimed it was possible to use the app in the primary care setting, and for $80 \%(8 / 10)$ of them it was easy to incorporate its use into the daily routine and home visits. Nevertheless, 70\% (7/10) of physicians claimed that the time taken to fill out the CDSS causes significant delays in service. Clinicians evaluated TeleHAS as good (8/10, 80\% 
of users), with easy completion and friendly interface $(10 / 10,100 \%)$ and the potential to improve patients' treatment $(10 / 10$, $100 \%)$. A total of $90 \%(9 / 10)$ of physicians had access to new knowledge about cardiovascular risk and hypertension through the app recommendations and found it useful to promote prevention and optimize treatment.

Conclusions: In this study, a CDSS developed to assist the management of patients with hypertension was feasible in the context of a primary health care setting in a middle-income country, with good user satisfaction and the potential to improve adherence to evidence-based practices.

(JMIR Mhealth Uhealth 2019;7(3):e9869) doi: 10.2196/mhealth.9869

\section{KEYWORDS}

telemedicine; clinical decision support system; cardiovascular disease; hypertension

\section{Introduction}

Hypertension is a major modifiable cardiovascular risk factor responsible for substantial morbidity and mortality worldwide. It causes around 9.4 million deaths every year [1]. According to the World Health Organization, the prevalence of this condition in adults older than 25 years is $29.2 \%$ in men and $24.8 \%$ in women [2], which results in a global prevalence of over 1 billion people. Despite this high prevalence, the blood pressure control levels are as low as $30 \%$ of treated patients worldwide [3].

In the last three decades, clinical practice guidelines addressing hypertension management invariably recommended that cardiovascular risk assessment must be a core feature of hypertension care [4-7]. Brazilian guidelines also recommend the systematic assessment of cardiovascular risk during hypertension management and the use of statins if needed [8]. Cardiovascular and cerebrovascular diseases are the leading causes of death in low- and middle-income countries (LMIC) [1], including Brazil [9], and are responsible for the increasing use of health system resources, quite often from preventable complications. Despite Brazilian Society of Cardiology recommendations on the use of multiple risk scores to assess cardiovascular risk and advocacy of the use of a global risk assessment based in the 10-year Framingham heart score risk $[8,10]$, Brazilian physician adherence to its use is poor [11].

To face these challenges, the health systems in LMIC struggle to improve their quality and overcome underfunding and lack of resources [12]. In Brazil, a large country with a decentralized health system, primary care physicians have limited access to point-of-care information resources that could assist clinical decision making and improve quality of care. In this context, mobile health (mHealth) technologies might be used to ease the access of health programs to a large number of individuals at relatively low cost [13-16]. When integrated to clinical decision support systems (CDSSs), mHealth technologies might increase the accuracy of diagnosis and treatment [12]. However, most studies were performed in high-income countries, implying that mHealth is still at an early stage of development in low-income countries [13,14,17].

Most of the literature that evaluated CDSSs in the management of hypertension focused on outcomes, with mixed results [18-22]. Despite the recommendation of international and Brazilian medical societies, few CDSSs addressing hypertension included the assessment of cardiovascular risk and few studies in LMIC evaluated what characteristics were responsible for implementation failure or success or addressed feasibility and user satisfaction in the primary care setting [23,24]. No study evaluated the use of a CDSS in the care of patients in Brazil. Thus, we conducted this study to develop a CDSS that integrates cardiovascular risk assessment, monitoring of blood pressure, nonpharmacological measures, and guidance to drug prescription. We also aimed to test the feasibility of implementing it in Brazilian primary care units as well as to assess its usability and utility, identifying facilities and barriers to its use.

\section{Methods}

\section{Design of the Study}

This study was conducted in four steps, according to the Medical Research Council framework [25].

\section{Identify Gaps in Usual Care Through Literature Review}

We assessed epidemiological studies and systematic reviews on hypertension management as well as feasibility studies, randomized controlled trials, and systematic reviews on CDSSs to evaluate which gaps were already known. Additionally, the topic was discussed in meetings with Brazilian health system stakeholders and primary care physicians to identify other issues.

\section{Identify Components of the Intervention Through Discussion With Experts}

Meetings and internal workshops were conducted to discuss the topic with primary care physicians. Primary care physicians, internal medicine specialists, cardiologists, and endocrinologists discussed the gaps with experts in information technology to identify solutions and components of an intervention.

\section{Clinical Decision Support System Development}

The CDSS, named TeleHAS (tele-hipertensão arterial sistêmica, or arterial hypertension system), was developed based in clinical practice guideline recommendations. Brazilian and international guidelines assessing hypertension as a main subject or in the context of other comorbidities such as diabetes or chronic renal disease [4,5,26-31] were reviewed, and clinical rules for hypertension and cardiovascular risk management were derived and organized into a decision tree (Multimedia Appendix 1). In case of conflicting recommendations, the one with the best level of evidence, most compelling recommendation, or latest publication was chosen. When a guideline recommendation was not available or was considered 
outdated, rules based on best scientific evidence were used, including evidence-based summaries, synopses, or syntheses. The decision tree was then organized as a CDSS on a modular basis and installed on a tablet using the Android 4.1 operating system.

The CDSS consists of a structured clinical evaluation assessing identification, medical history, physical examination, current medications, and laboratory and image test results (Textbox 1). Only the patient name and date of birth were considered mandatory fields. The interface was developed to be intuitive and self-explanatory. Data requested were manually entered and included variables of interest in the management of hypertensive patients: blood pressure, lipid profile, renal function tests, microalbuminuria or proteinuria, liver enzyme tests, and electrocardiogram, among others. Body mass index, estimated glomerular filtration rate using the Cockcroft-Gault formula [32], and cardiovascular risk based on the Framingham score [33] were calculated using the data entered and displayed immediately on screen. After data are entered, the CDSS presents suggestions and recommendations about pharmacologic and nonpharmacologic interventions including physical activity, diet recommendations, and medication dosages and interactions (Figures 1 and 2).

After patient registration, any subsequent consultation was recorded in the database in a file under the patient name. Data were recorded in TeleHAS and transmitted to a telehealth care central whenever internet connection was available. The CDSS was updated if problems were identified. A Web-based data panel was developed to help researchers access the database.

The CDSS was electronically tested to verify that recommendation results matched the prespecified decision tree. Manual insertion of data by a physician was later performed to verify the recommendation response suitability. After adjustments, TeleHAS was submitted for analysis to an expert panel comprising 2 cardiologists and 3 primary care physicians, known as technical reference, for a period of 7 days. Structured questionnaires and semistructured interviews were used to assess strengths, inconsistencies, and satisfaction with the device use. The participants were asked to classify their general impression of the CDSS as very appropriate, appropriate, indifferent, or inappropriate. It was then readjusted with the necessary changes according to the criticisms and suggestions from the expert panel.

Textbox 1. The five main menus of TeleHAS.

- Identification: patient name, date of birth, mother's name, and sex

- Comorbidities: may be used to select other diseases or risk factors presented by the patient

- Physical exam: blood pressure, waist circumference, weight, and height

- Laboratory studies: lipid profile, biochemical panel, echocardiography, and electrocardiography data

- Medications: several blood pressure medications categorized by class

Figure 1. TeleHAS open screen and main menu.
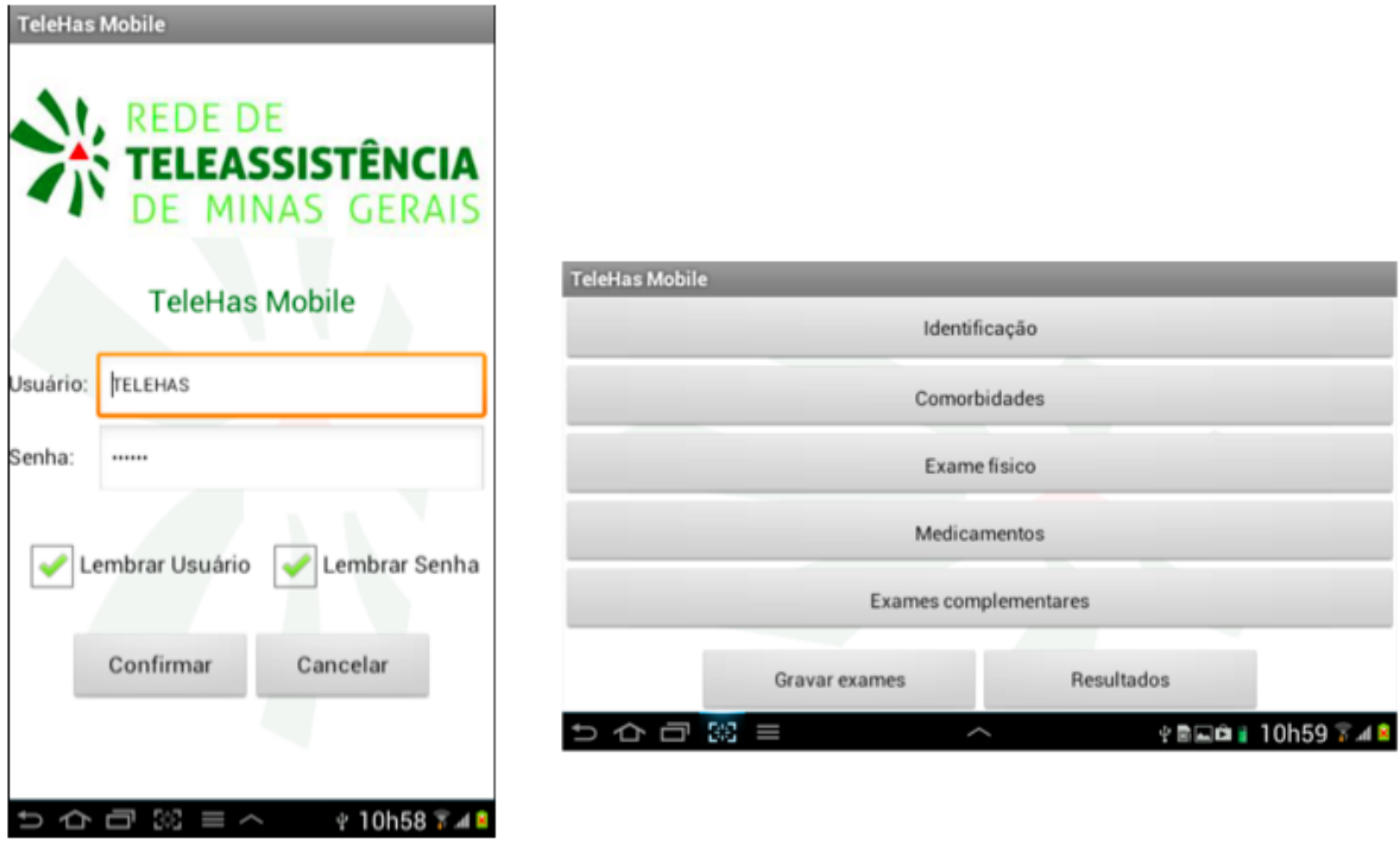
Figure 2. TeleHAS previous diseases and alerts menu.

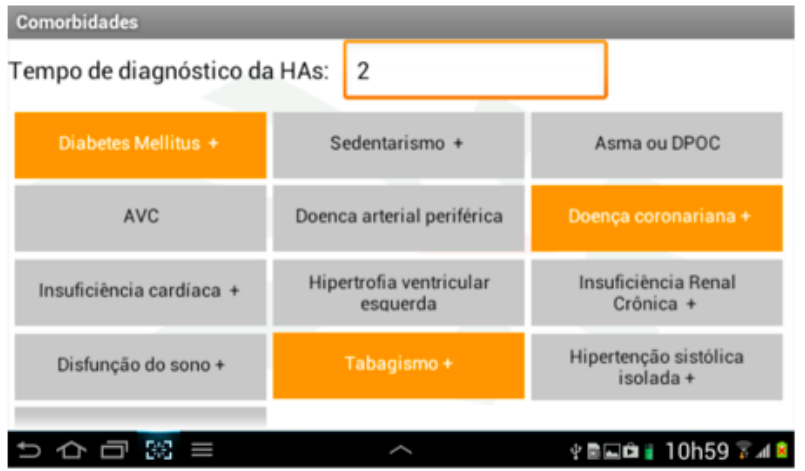

\section{Evaluate Feasibility Through Field Study}

The field study was conducted in Montes Claros, the largest city in the north of the Minas Gerais state (population 361,000), 270 miles north of the state's capital. It has a human development index of 0.77 [34], slightly above the Brazilian average. The municipal primary care system is composed of 88 primary health centers in urban and rural areas with health teams composed by one physician and one nurse and a variable number of community health workers. Despite the existence of a university and two medical schools, clinicians have limited access to specialist referral and continuing education due to the distance to the country's main centers.

All 66 primary care physicians from Montes Claros were invited to attend a lecture on hypertension diagnosis and management. Of the 63 attendees, 51 agreed to join the study and 10 were randomly selected. The selected doctors used TeleHAS in

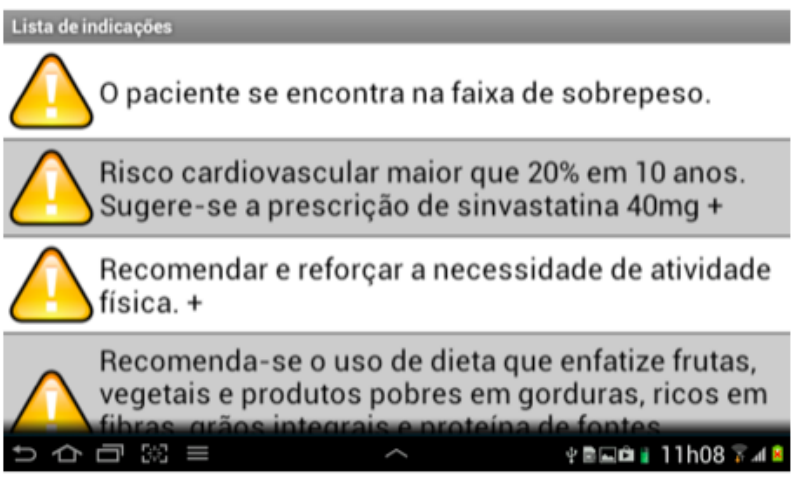

routine care of hypertensive patients to build up their impressions about the CDSS for 6 months. Physicians planned and individualized the frequency of blood pressure measurements for each patient.

A nurse and an information technology technician held biweekly visits to address issues and resolve difficulties in the CDSS use and allow data transfer to the TeleHAS network server through a $3 \mathrm{G}$ connection available only on the nurse's tablet due to its high cost in Brazil.

Paper-based questionnaires evaluating feasibility, usability, and utility of the CDSS were developed and applied with semistructured interviews at the end of 3 and 6 months (Figure 3 ). Perceived feasibility, usability, and utility questions were rated on a Likert scale from 1 (strongly disagree) to 5 (strongly agree) [35]. The final score was defined as the mean of the scores for all of the questions.

Figure 3. Study design.

\section{Selection of participants: 10 primary care physicians randomly selected among} all primary care physicians in Montes Claros - Brazil

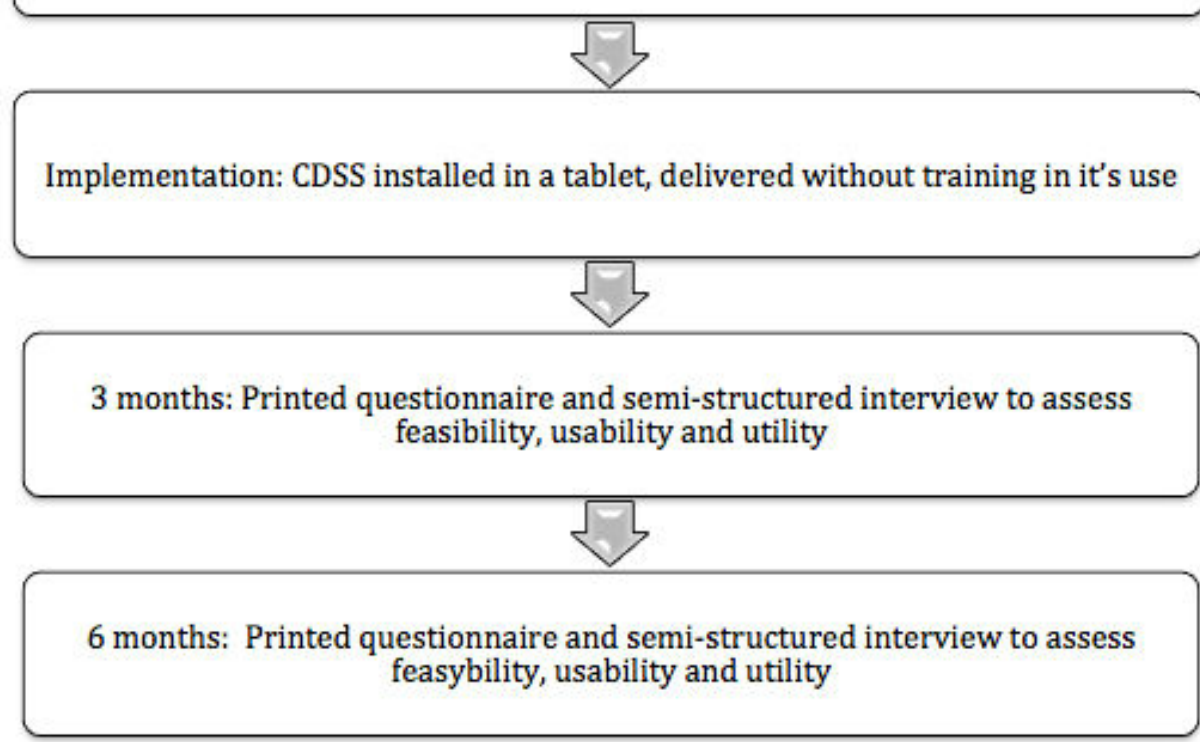




\section{Data Analysis}

Categorical variables were presented as frequencies and proportions. As the sample size of physicians was small, continuous variables were expressed as median and interquartile range. Data analyses were performed using SPSS Statistics for Windows version 21.0 (IBM Corp).

\section{Ethics Statement}

The study was approved by the ethics committee of the Universidade Federal de Minas Gerais, Minas Gerais, Brazil. Informed, written consent was obtained from all participants contributing data to the study.

\section{Results}

\section{Expert Panel}

All specialists considered the initial menu, identification, comorbidities, medicine, and complementary exam screens as adequate (Table 1). Doctors unanimously considered the TeleHAS interface, alert content, appearance, and speed of alert generation adequate. They generally reported that TeleHAS used the best available evidence and suggested changes based on literature or use of alternative guidelines when needed. The suggested changes were incorporated in the software.

Specialists perceived TeleHAS as an intervention that could change clinical practice.

The CDSS helps in the process of decision making for treatment of patients with hypertension, both in pharmacologic and nonpharmacologic therapy. [Family physician]

\section{I believe it can be very helpful to control high blood pressure. [Cardiologist]}

There was a unanimous impression that the device has the potential to deliver updated information to health care providers and education promotion is a major feature of its use. It was highlighted that the device has the potential to promote implementation of evidence-based recommendations.

Great potential to promote best scientific evidence implementation for the individual patient. [Family physician]
When asked about the feasibility of TeleHAS in the clinical setting, all participants agreed it was feasible.

TeleHAS has the potential to improve clinical practice quality, and it's applicable to the routine of primary care services. [Family physician]

One primary care physician considered the physical exam screen inadequate. He stated that he would like to enter data about other conditions not associated with hypertension or cardiovascular risk such as glycemic control and data from skin, respiratory, and abdomen semiology. He suggested that a free-text field could be added to address this demand.

\section{Field Study}

Participant characteristics are described in Table 2. Age varied from 27 to 59 years (median 31 years). The median length of professional experience in a primary care setting was 2.5 years (ranging from 0 to 20 years) and time working in the municipality was 1.5 years.

During the 6 months of field study, participant physicians registered 535 patients in the TeleHAS database and performed 632 consultations.

\section{Feasibility, Usability, and Utility}

Quantitative analysis of impressions for feasibility, usability, and utility is described in Tables 3-5.

Although doctors were motivated to use TeleHAS, finding the time to enter data was a major concern. Physicians believed it caused significant delay in the daily routine and developed alternative forms of use to deal with this challenge. Some used the CDSS in educational groups and on days specifically scheduled to attend patients with hypertension. Others used it daily when attending a patient with hypertension. Due to the scarce time available, some of them attended patients without the CDSS and filled it out later, saving remarks for the next appointment. In the case of one clinician, this choice was due to fear of patient opinion.

...I was concerned that they might find I was distracted or writing something else, like sending messages during the consultation. [Clinician]

Work duplication was also identified as a problem, and clinicians demanded a printed handout to deliver to patients and attach to the patient record at the end of the consultation.

Table 1. Expert panel perception of TeleHAS for each screen $(n=5)$.

\begin{tabular}{llll}
\hline Screen & $\begin{array}{l}\text { Rating } \\
\text { Very adequate, } \mathrm{n}(\%)\end{array}$ & Adequate, $\mathrm{n}(\%)$ & Inadequate, $\mathrm{n}(\%)$ \\
\hline Initial menu & $3(60)$ & $2(40)$ & $0(0)$ \\
Identification & $3(60)$ & $2(40)$ & $0(0)$ \\
Comorbidities & $1(20)$ & $4(80)$ & $0(0)$ \\
Physical exam & $0(0)$ & $4(80)$ & $1(20)$ \\
Medicine & $2(40)$ & $3(60)$ & $0(0)$ \\
Complementary exams & $1(20)$ & $4(80)$ & $0(0)$ \\
\hline
\end{tabular}


Table 2. Characteristics of primary care physicians in the study $(\mathrm{n}=10)$.

\begin{tabular}{|c|c|}
\hline Variable & Value, $\mathrm{n}(\%)$ \\
\hline Sex, female & $8(80)$ \\
\hline \multicolumn{2}{|l|}{ Time since graduation (years) } \\
\hline$<5$ & $7(70)$ \\
\hline $5-10$ & $1(10)$ \\
\hline$>10$ & $2(20)$ \\
\hline \multicolumn{2}{|l|}{ Specialty } \\
\hline Angiology & $1(10)$ \\
\hline Family medicine & $2(20)$ \\
\hline Geriatrics & $1(10)$ \\
\hline Occupational medicine & $1(10)$ \\
\hline Pediatrics & $1(10)$ \\
\hline None $^{\mathrm{a}}$ & $4(40)$ \\
\hline \multicolumn{2}{|l|}{ Self-reported knowledge of information technology } \\
\hline Inadequate & $2(20)$ \\
\hline Satisfactory & $4(40)$ \\
\hline Good & $3(30)$ \\
\hline Excellent & $1(10)$ \\
\hline Use of any form of technology before TeleHAS, yes & $9(90)$ \\
\hline Computer available in the workplace for routine use, yes & $0(0)$ \\
\hline Internet access in the workplace, yes & $5(50)$ \\
\hline \multicolumn{2}{|l|}{ Internet use frequency } \\
\hline Daily & $9(90)$ \\
\hline Monthly & $1(10)$ \\
\hline Completed continuing education on management of hypertension or cardiovascular risk in the last year, yes & $6(60)$ \\
\hline \multicolumn{2}{|l|}{ Major sources of continuing education } \\
\hline Guidelines & $3(30)$ \\
\hline Books & $2(20)$ \\
\hline Articles & $1(10)$ \\
\hline Congress & $1(10)$ \\
\hline
\end{tabular}

${ }^{\mathrm{a}}$ Residency is not a prerequisite for doctors who work in primary care in Brazil.

Table 3. Feasibility score on a 5 -point scale by item $(n=10)$.

\begin{tabular}{ll}
\hline Item & Score mean \\
\hline The CDSS $^{\text {a can be used in the primary care setting. }}$ & 4.5 \\
It can be used in home visits. & 4.2 \\
It is easy to incorporate in work routine. & 4.0 \\
Internet connection is not essential for the use of the CDSS. & 3.6 \\
The CDSS does not cause significant delays in daily routine. & 3.0 \\
\hline
\end{tabular}

${ }^{\mathrm{a}}$ CDSS: clinical decision support system. 
Table 4. Usability score on a 5-point scale by item $(n=10)$.

\begin{tabular}{lc}
\hline Item & Score mean \\
\hline My overall evaluation of the CDSS ${ }^{\mathrm{a}}$ is good. & 4.5 \\
The CDSS screens are easy to understand. & 4.5 \\
The definitions of comorbidities are clear and unambiguous. & 4.1 \\
The CDSS fields are easy to complete. & 4.3 \\
The CDSS is intuitive and requires no previous training to use. & 3.4 \\
The CDSS is stable, and no errors occur during use. & 3.0 \\
\hline
\end{tabular}

${ }^{\mathrm{a} C D S S}$ : clinical decision support system.

Table 5. Utility score on a 5-point scale by item $(n=10)$.

\begin{tabular}{lc}
\hline Item & Score mean \\
\hline I believe that the $\mathrm{CDSS}^{\mathrm{a}}$ might improve the treatment of hypertensive patients. & 4.5 \\
Reading the recommendations of the CDSS, I had access to new information on hypertension and cardiovascular risk. & 4.1 \\
According to my previous knowledge, I believe the recommendations generated by the CDSS are appropriate. & 4.1 \\
The CDSS was useful to calculate the cardiovascular risk of hypertensive patients. & 3.8 \\
The CDSS was useful to promote cardiovascular disease prevention actions among my patients. & 4.3 \\
The CDSS helped me treat my patients. & 4.6 \\
I used the recommendations to modify the behavior of my patients. & 4.0 \\
I would recommend the CDSS to my colleagues. & 4.7 \\
\hline
\end{tabular}

${ }^{\mathrm{a}}$ CDSS: clinical decision support system.

With regard to usability, during the interviews, all physicians classified the identification screen as practical and simple to use. Clinicians also reported the comorbidities screen as simple and intelligible.

Although TeleHAS was designed to be intuitive, some physicians believed training was essential for its proper use, even though clinicians did explore its features and learned the hidden tasks it was designed to do (eg, the majority found out that date of birth could be inserted by the keyboard or by a cursor displayed after continuously pressing the data field).

Most clinicians stated that other chronic conditions should be addressed in the CDSS and requested the option to enter glucose levels, diabetes mellitus complications such as diabetic foot, and other classes of medication for associated conditions such as methimazole, insulin, metformin, isosorbide and cilostazol.

Some clinicians observed errors during CDSS use. The most discussed one was that the software would sometimes stop working. This was due to a fault in the Android system that would stop functioning if the tablet enter key was pressed twice. No primary health care center had Wi-Fi connection available. System actualizations and data transfer to the TeleHAS database server occurred whenever Wi-Fi connection was available, at the physician's home or during the visit by the nurse and information technology technician. Eventually, due to the absence of $3 \mathrm{G}$ coverage or inadequate connection speed, the nurse needed to set up an appointment with the physician in the city to proceed with data transfer.
With regard to utility, physicians reported that TeleHAS eventually changed clinical practice. Some of them changed their blood pressure measurement techniques by reading the description available in the CDSS. Others started to measure blood pressure in 3 positions to complete all the fields available in TeleHAS.

For the physical exam screen, clinicians suggested a change in the sequence available in the CDSS, as they normally make the first measure with the patient seated.

Sometimes I entered the measure in the wrong field, because I start with the patient seated. Then I had to enter the measures again, after other measures. [Family physician]

It was perceivable that clinicians worked with different levels of systematization. Only three of them calculated cardiovascular risk systematically using the 10-year global risk assessment score chart. Physicians perceived TeleHAS as helpful in promoting cardiovascular risk assessment and prevention actions.

Some clinicians perceived the CDSS fulfillment and recommendations delivered as repetitive.
After a while, you get tired of reading the same things. You don't have much time available [to deal with the repetitive content]. [Clinician]

However, some considered the repetition a CDSS strength. 
Sometimes we remember to guide the patient only about medication, and we forget to talk about nonpharmacologic treatment. The alerts are repetitive, but it helps us to remember. [Family physician]

I used to forget to ask about the salt in their diet. With the CDSS, I remembered to ask about it with every patient. [Geriatrics]

The accuracy of the CDSS cardiovascular risk calculation was considered unsatisfactory by $30 \%$ (3/10) of participants. In the interviews, this issue was often discussed. The clinicians reported that the cardiovascular risk calculator sometimes presented spurious results and made them confused about the correct estimated risk. This error was found to occur when the date of birth was not entered or entered incorrectly.

\section{Discussion}

\section{Principal Findings}

This field study designed to evaluate the feasibility and usability of a CDSS to assist hypertension and cardiovascular risk management found that it is feasible to implement such technology in a primary care setting in a middle-income country with good satisfaction by health professionals. Equally important, the study elicited strengths and faults of the CDSS and helped identify facilities and barriers for TeleHAS implementation.

In Brazil, primary care physicians are commonly young and inexperienced doctors, frequently recently graduated [36,37], and in this study the majority of participants were women with less than 5 years of professional experience after graduation. Participant clinicians' profiles were variable regarding clinical experience and expertise, clinical specialty, intimacy with information technology, and forms of knowledge update. Primary care physicians often used the CDSS in their work routine and inserted a large amount of data in the TeleHAS database. They reported having learned new skills and knowledge through TeleHAS, felt comfortable using its guidance to change their practice and make clinical decisions, and rated the CDSS as having good usability and usefulness for knowledge dissemination, with potential influence for better hypertension management.

This feasibility study showed several barriers for the implementation of TeleHAS, including health professional issues, telecommunication structure, and health system infrastructure. Physician resistance to adopting information technologies is one of the main barriers for implementation, often due to poor satisfaction with physical characteristics of digital technologies, difficulties with their use, and low effectiveness of devices [38]. In our TeleHAS evaluation, clinicians reported good satisfaction with the CDSS, and it is presumable that this will facilitate its use in large scale. In this sample, the previous use of information technology was low. Clinicians did have some difficulties managing the software and tablet, and although it did not deeply affect the use of the CDSS, some physicians had the perception that training would be needed for TeleHAS use. More effort should be made to improve the CDSS to make it as intuitive as possible for better scalability.

With regard to the telecommunication structure, problems with internet connection, poor broadband coverage, and high cost of 3G limited data transfer to the TeleHAS database server. Problems in telecommunication structures that limit dissemination of mHealth services in LMIC are similar to those seen in LMIC medical care, like services limited in scope, unevenly distributed across geographic areas, and of variable quality when available [39]. This issue was mitigated because TeleHAS was designed to function without an internet connection, but it is still required for data transmission and system update. Support by government policies to improve the quality of telecommunication structure is important to avoid future greater limitations for TeleHAS use.

Barriers to CDSS use were also identified. Low computerization of the primary health centers was a major limitation for the CDSS implementation. There was a perceptible demand for communication technologies in primary health system and much of the demand presented by physicians was related to the need to register and organize patient records and clinical data. This is in agreement with CDSS usability tests performed previously. In a study to assess the usability of a CDSS for the management of diabetes, the absence of electronic medical records was also pointed out as a major barrier for system definitive implementation in primary care [40]. Combination of CDSS with electronic health records, communication technologies integration in the structure of health care, and progressive computerization of primary health centers should stimulate use of these technologies.

Another major barrier for TeleHAS use in primary care was health professionals' excessive workload. The work duplication generated by the need to register data in the tablet and in the patient records limited the use of the CDSS. In a meta-analysis of 311 unique studies on CDSSs, including 148 randomized controlled trials, several features have shown to be predictors of improved health care process measures, including integration with charting or order entry system with no need for additional clinician data entry [41]. Although TeleHAS was developed to be fully integrated into primary health care routine, its use as part of clinician workflow must improve to avoid work duplication. This was not possible at that time due to the fact that all primary care units, just like the majority of primary care units in Brazil, still use paper-based patient records. In the expert panel, a primary care physician suggested a free-text field to allow data entry of other conditions. As it was not our goal to substitute the paper-based patient records at that time, we opted not to make the change, but we included it in an updated version of TeleHAS. Despite the work duplication that we could not avoid, clinicians reported that it was possible to use the CDSS in their work routine and managed to find alternative ways to use it. A feasibility study of an mHealth app to assist nurses in the management of hypertension also found that professionals with heavy workloads felt the app demanded work duplication and was an extra burden in an already increasing workload [23]. Integration of the CDSS with the electronic health record in the primary care workflow may improve usability and reduce health 
professionals' workload issues, enhancing its impact in clinical practice.

Task shifting to other health professionals is proposed as a solution to improve quality of care in chronic diseases. CDSSs designed to integrate the work of health professionals have been developed and may be the way for TeleHAS to diminish data entry requirements by clinicians. In a study performed in India, physicians and community health workers used a CDSS designed to address hypertension and assess cardiovascular risk. It was observed that such technology might aid to standardize the care and empower other health workers to help in cardiovascular risk assessment and patient care [24]. Care in primary health centers is unequal, as clinicians work with different strategies and environments and have different levels of knowledge and clinical experience. Despite the cardiovascular risk calculation in TeleHAS having errors and confusing some of the clinicians, the majority found the CDSS useful to calculate and manage the patients' cardiovascular risk. This was probably because not all physicians performed systematic cardiovascular risk assessment before TeleHAS use, and this became part of their routine practice after they started using the CDSS. By asking for standardized data entry and providing repeated reminders about health care, mHealth technologies such as TeleHAS may help in health care standardization.

This study was designed to test and improve a CDSS and used qualitative assessments rather than clinical outcomes. However, its findings are very important, as usability testing is an essential step before software implementation in clinical practice or testing the impact in clinical outcomes. Poor usability may lead to various undesirable effects, ranging from user dissatisfaction and failed implementations to endangered patient safety [42]. This step was essential to test if TeleHAS was properly designed, assess its acceptance by the physicians, identify the necessity of improvements, and strengthen the CDSS for better adaptation to face the challenges for its implementation in clinical practice in order to obtain better results in blood pressure control and clinical outcomes. Data from individual patients were not addressed, so it is not possible to analyze the characteristics of the population in which the CDSS was applied or assess the impression of patients on the CDSS use by a clinician. The CDSS was improved, with optimization in the design of the screens and cardiovascular risk assessment and increased participation of health care practitioners other than doctors. The alerts were updated and information on diabetes control was added. Its impact on hypertension and diabetes control is being assessed in a large-scale study in 39 primary care units. Usability assessment will be performed with all health care practitioners in order to have a more representative sample of Brazilian primary care professionals.

\section{Conclusions}

In this study, a CDSS developed to assist in decision making in hypertension and cardiovascular risk assessment was feasible in the context of the primary care setting, with good user satisfaction and possible positive impact on the implementation of guidelines, recommendations, and best available evidence. The study provided the opportunity to strengthen TeleHAS to face the barriers identified in its implementation. The CDSS is currently being tested in a large-scale clinical study to access clinical end points and the possibility to scale up its use for the primary care setting within the country and in other LMIC.

\section{Acknowledgments}

This study was supported by the Brazilian research agencies Financiadora de Estudos e Projetos (FINEP), Fundação de Amparo à Pesquisa de Minas Gerais (FAPEMIG), and Conselho Nacional de Desenvolvimento Científico e Tecnológico (CNPq). ALPR receives unrestricted grants from CNPq and FAPEMIG, DVS received a scholarship from FAPEMIG, ELM received a scholarship from the Brazilian research agency Coordenação de Aperfeiçoamento de Pessoal de Nivel Superior, BCC and CGF received a scholarship from FAPEMIG, and MBMA received a scholarship from FINEP.

\section{Conflicts of Interest}

None declared.

\section{Multimedia Appendix 1}

Example of TeleHAS decision tree.

[PDF File (Adobe PDF File), 66KB-Multimedia Appendix 1]

\section{References}

1. Lim SS, Vos T, Flaxman AD, Danaei G, Shibuya K, Adair-Rohani H, et al. A comparative risk assessment of burden of disease and injury attributable to 67 risk factors and risk factor clusters in 21 regions, 1990-2010: a systematic analysis for the Global Burden of Disease Study 2010. Lancet 2012 Dec 15;380(9859):2224-2260 [FREE Full text] [doi: 10.1016/S0140-6736(12)61766-8] [Medline: 23245609]

2. World Health Organization. World Health Statistics 2012 URL: https://www.who.int/gho/publications/world health statistics/ 2012/en/ [accessed 2019-01-18] [WebCite Cache ID 76mEE9F97]

3. Chow CK, Teo KK, Rangarajan S, Islam S, Gupta R, Avezum A, et al. Prevalence, awareness, treatment, and control of hypertension in rural and urban communities in high-, middle-, and low-income countries. JAMA 2013 Sep 04;310(9):959-968. [doi: 10.1001/jama.2013.184182] [Medline: 24002282] 
4. Mancia G, Fagard R, Narkiewicz K, Redon J, Zanchetti A, Böhm M, et al. 2013 ESH/ESC guidelines for the management of arterial hypertension: the Task Force for the Management of Arterial Hypertension of the European Society of Hypertension (ESH) and of the European Society of Cardiology (ESC). Eur Heart J 2013 Jul;34(28):2159-2219 [FREE Full text] [doi: 10.1093/eurheartj/eht151] [Medline: 23771844]

5. James PA, Oparil S, Carter BL, Cushman WC, Dennison-Himmelfarb C, Handler J, et al. 2014 evidence-based guideline for the management of high blood pressure in adults: report from the panel members appointed to the Eighth Joint National Committee (JNC 8). JAMA 2014 Feb 5;311(5):507-520. [doi: 10.1001/jama.2013.284427] [Medline: 24352797]

6. Aronow WS, Fleg JL, Pepine CJ, Artinian NT, Bakris G, Brown AS, ACCF Task Force. ACCF/AHA 2011 expert consensus document on hypertension in the elderly: a report of the American College of Cardiology Foundation Task Force on Clinical Expert Consensus Documents. Circulation 2011 May 31;123(21):2434-2506 [FREE Full text] [doi:

10.1161/CIR.0b013e31821daaf6] [Medline: 21518977]

7. Rosendorff C, Black HR, Cannon CP, Gersh BJ, Gore J, Izzo JL, American Heart Association Council for High Blood Pressure Research, American Heart Association Council on Clinical Cardiology, American Heart Association Council on Epidemiology and Prevention. Treatment of hypertension in the prevention and management of ischemic heart disease: a scientific statement from the American Heart Association Council for High Blood Pressure Research and the Councils on Clinical Cardiology and Epidemiology and Prevention. Circulation 2007 May 29;115(21):2761-2788 [FREE Full text] [doi: 10.1161/CIRCULATIONAHA.107.183885] [Medline: 17502569]

8. Faludi AA, Izar MC, Saraiva JFK, Chacra APM, Bianco HT, Afiune A, et al. Atualização da Diretriz Brasileira de Dislipidemias e Prevenção da Aterosclerose-2017. Arq Bras Cardiol 2017 Jul;109(2 Supl 1):1-76 [FREE Full text] [doi: 10.5935/abc.20170121] [Medline: 28813069]

9. Ribeiro ALP, Duncan BB, Brant LCC, Lotufo PA, Mill JG, Barreto SM. Cardiovascular health in Brazil: trends and perspectives. Circulation 2016 Jan 26;133(4):422-433 [FREE Full text] [doi: 10.1161/CIRCULATIONAHA.114.008727] [Medline: 26811272]

10. Xavier HT, Izar MC, Faria Neto JR, Assad MH, Rocha VZ, Sposito AC, et al. V Brazilian Guidelines on Dyslipidemias and Prevention of Atherosclerosis. Arq Bras Cardiol 2013 Dec;101(4 Suppl 1):1-20 [FREE Full text] [doi: 10.5935/abc.2013S010] [Medline: 24217493]

11. Sposito AC, Ramires JAF, Jukema JW, Molina JC, da Silva PM, Ghadanfar MM, et al. Physicians' attitudes and adherence to use of risk scores for primary prevention of cardiovascular disease: cross-sectional survey in three world regions. Curr Med Res Opin 2009 May;25(5):1171-1178. [doi: 10.1185/03007990902846423] [Medline: 19323611]

12. Mechael PB, Kaonga N, Searle S, Kwan A, Goldberger A. Barriers and gaps affecting mHealth in low and middle income countries: policy white paper. 2010. URL: http://www.globalproblems-globalsolutions-files.org/pdfs/ mHealth Barriers White Paper.pdf [accessed 2019-01-18] [WebCite Cache ID 75WogW0Kd]

13. Xiong S, Berkhouse H, Schooler M, Pu W, Sun A, Gong E, et al. Effectiveness of mhealth interventions in improving medication adherence among people with hypertension: a systematic review. Curr Hypertens Rep 2018 Aug 07;20(10):86. [doi: 10.1007/s11906-018-0886-7] [Medline: 30088110]

14. Marcolino MS, Oliveira JAQ, D'Agostino M, Ribeiro AL, Alkmim MBM, Novillo-Ortiz D. The impact of mHealth interventions: systematic review of systematic reviews. JMIR Mhealth Uhealth 2018 Jan 17;6(1):e23 [FREE Full text] [doi: 10.2196/mhealth.8873] [Medline: 29343463]

15. Oldenburg B, Taylor CB, O'Neil A, Cocker F, Cameron LD. Using new technologies to improve the prevention and management of chronic conditions in populations. Annu Rev Public Health 2015 Mar 18;36:483-505. [doi: 10.1146/annurev-publhealth-031914-122848] [Medline: 25581147]

16. Arditi C, Rège-Walther M, Wyatt JC, Durieux P, Burnand B. Computer-generated reminders delivered on paper to healthcare professionals: effects on professional practice and health care outcomes. Cochrane Database Syst Rev 2012;12:CD001175. [doi: 10.1002/14651858.CD001175.pub3] [Medline: 23235578]

17. Alessa T, Abdi S, Hawley MS, de Witte L. Mobile apps to support the self-management of hypertension: systematic review of effectiveness, usability, and user satisfaction. JMIR Mhealth Uhealth 2018 Jul 23;6(7):e10723 [FREE Full text] [doi: 10.2196/10723] [Medline: 30037787 ]

18. Stephani V, Opoku D, Quentin W. A systematic review of randomized controlled trials of mHealth interventions against non-communicable diseases in developing countries. BMC Public Health 2016 Dec 15;16:572 [FREE Full text] [doi: 10.1186/s12889-016-3226-3] [Medline: 27417513]

19. Shojania KG, Jennings A, Mayhew A, Ramsay CR, Eccles MP, Grimshaw J. The effects of on-screen, point of care computer reminders on processes and outcomes of care. Cochrane Database Syst Rev 2009 Jul 08(3):CD001096 [FREE Full text] [doi: 10.1002/14651858.CD001096.pub2] [Medline: $\underline{19588323}$ ]

20. Garg AX, Adhikari NKJ, McDonald H, Rosas-Arellano MP, Devereaux PJ, Beyene J, et al. Effects of computerized clinical decision support systems on practitioner performance and patient outcomes: a systematic review. JAMA 2005 Mar 9;293(10):1223-1238. [doi: 10.1001/jama.293.10.1223] [Medline: 15755945]

21. Bright TJ, Wong A, Dhurjati R, Bristow E, Bastian L, Coeytaux RR, et al. Effect of clinical decision-support systems: a systematic review. Ann Intern Med 2012 Jul 3;157(1):29-43. [doi: 10.7326/0003-4819-157-1-201207030-00450] [Medline: $\underline{22751758]}$ 
22. Anchala R, Kaptoge S, Pant H, Di Angelantonio E, Franco OH, Prabhakaran D. Evaluation of effectiveness and cost-effectiveness of a clinical decision support system in managing hypertension in resource constrained primary health care settings: results from a cluster randomized trial. J Am Heart Assoc 2015 Jan 05;4(1):e001213 [FREE Full text] [doi: 10.1161/JAHA.114.001213] [Medline: 25559011]

23. Vedanthan R, Blank E, Tuikong N, Kamano J, Misoi L, Tulienge D, et al. Usability and feasibility of a tablet-based Decision-Support and Integrated Record-keeping (DESIRE) tool in the nurse management of hypertension in rural western Kenya. Int J Med Inform 2015 Mar;84(3):207-219 [FREE Full text] [doi: 10.1016/j.ijmedinf.2014.12.005] [Medline: 25612791]

24. Praveen D, Patel A, Raghu A, Clifford GD, Maulik PK, Mohammad AA, et al. SMARTHealth India: development and field evaluation of a mobile clinical decision support system for cardiovascular diseases in rural India. JMIR Mhealth Uhealth 2014 Dec 08;2(4):e54 [FREE Full text] [doi: 10.2196/mhealth.3568] [Medline: 25487047]

25. Craig P, Dieppe P, Macintyre S, Michie S, Nazareth I, Petticrew M. Developing and evaluating complex interventions: the new Medical Research Council guidance. BMJ 2008;337:a1655 [FREE Full text] [Medline: 18824488]

26. Dasgupta K, Quinn RR, Zarnke KB, Rabi DM, Ravani P, Daskalopoulou SS, et al. The 2014 Canadian Hypertension Education Program recommendations for blood pressure measurement, diagnosis, assessment of risk, prevention, and treatment of hypertension. Can J Cardiol 2014 May;30(5):485-501 [FREE Full text] [doi: 10.1016/j.cjca.2014.02.002] [Medline: 24786438]

27. Reiner Z, Catapano AL, Graham I, Taskinen M, Wiklund O, Agewall S, et al. ESC/EAS Guidelines for the management of dyslipidaemias: the Task Force for the management of dyslipidaemias of the European Society of Cardiology (ESC) and the European Atherosclerosis Society (EAS). Eur Heart J 2011 Jul;32(14):1769-1818 [FREE Full text] [doi: 10.1093/eurheartj/ehr158] [Medline: 21712404]

28. American Diabetes Association. Standards of medical care in diabetes-2014. Diabetes Care 2014 Jan;37 Suppl 1:S14-S80. [doi: 10.2337/dc14-S014] [Medline: 24357209]

29. Perk J, Gohlke H, Graham I, Reiner Z, Verschuren M, Albus C, et al. European Guidelines on cardiovascular disease prevention in clinical practice (version 2012). The Fifth Joint Task Force of the European Society of Cardiology and Other Societies on Cardiovascular Disease Prevention in Clinical Practice (constituted by representatives of nine societies and by invited experts). Eur Heart J 2012 Jul;33(13):1635-1701 [FREE Full text] [doi: 10.1093/eurheartj/ehs092] [Medline: 22555213]

30. Royal College of Physicians. Hypertension: The Clinical Management of Primary Hypertension in Adults: Update of Clinical Guidelines 18 and 34. National Institute for Health and Clinical Excellence 2011. [Medline: 22855971]

31. Cadernos de Atenção Básica, n. 37. Estraté gias para o cuidado da pessoa com doenc sa cro^nica: hipertensa o arterial siste^mica URL: http://bvsms.saude.gov.br/bvs/publicacoes/estrategias cuidado pessoa doenca cronica.pdf [accessed 2019-01-18] [WebCite Cache ID 75WpjFuB3]

32. Cockcroft DW, Gault MH. Prediction of creatinine clearance from serum creatinine. Nephron 1976;16(1):31-41. [Medline: 1244564]

33. D'Agostino RB, Vasan RS, Pencina MJ, Wolf PA, Cobain M, Massaro JM, et al. General cardiovascular risk profile for use in primary care: the Framingham Heart Study. Circulation 2008 Feb 12;117(6):743-753 [FREE Full text] [doi: 10.1161/CIRCULATIONAHA.107.699579] [Medline: 18212285]

34. Instituto Brasileiro de Geografia e Estatísticas Cidades. URL: https://cidades.ibge.gov.br/brasil/mg/montes-claros/panorama [accessed 2018-11-02] [WebCite Cache ID 73dq8Gond]

35. Platts K. A process approach to researching manufacturing strategy. Int J Op Prod Manag 1993 Aug;13(8):4-17. [doi: $10.1108 / 01443579310039533]$

36. Paim J, Travassos C, Almeida C, Bahia L, Macinko J. The Brazilian health system: history, advances, and challenges. The Lancet 2011 May;377(9779):1778-1797. [doi: 10.1016/S0140-6736(11)60054-8]

37. Scheffer M, Biancarelli A. Conselho Regional de Medicina do Estado de São Paulo. Demografia Médica no Brasil 2018 URL: https://jornal.usp.br/wp-content/uploads/DemografiaMedica2018.pdf [accessed 2019-01-18] [WebCite Cache ID $\underline{75 \mathrm{WqQUCaU}}$

38. Lu Y, Xiao Y, Sears A, Jacko JA. A review and a framework of handheld computer adoption in healthcare. Int J Med Inform 2005 Jun;74(5):409-422. [doi: 10.1016/j.ijmedinf.2005.03.001] [Medline: 15893264]

39. Piette JD, List J, Rana GK, Townsend W, Striplin D, Heisler M. Mobile health devices as tools for worldwide cardiovascular risk reduction and disease management. Circulation 2015 Nov 24;132(21):2012-2027. [doi:

10.1161/CIRCULATIONAHA.114.008723] [Medline: 26596977]

40. Maia JX, de Sousa LAP, Marcolino MS, Cardoso CS, da Silva JLP, Alkmim MBM, et al. The impact of a clinical decision support system in diabetes primary care patients in a developing country. Diabetes Technol Ther 2016 Apr;18(4):258-263. [doi: 10.1089/dia.2015.0253] [Medline: 26840128]

41. Lobach D, Sanders GD, Bright TJ, Wong A, Dhurjati R, Bristow E, et al. Enabling health care decisionmaking through clinical decision support and knowledge management. Evid Rep Technol Assess (Full Rep) 2012 Apr(203):1-784. [Medline: 23126650] 
42. Russ AL, Baker DA, Fahner WJ, Milligan BS, Cox L, Hagg HK, et al. A rapid usability evaluation (RUE) method for health information technology. AMIA Annu Symp Proc 2010 Nov 13;2010:702-706 [FREE Full text] [Medline: 21347069]

\title{
Abbreviations
}

CDSS: clinical decision support system

CNPq: Conselho Nacional de Desenvolvimento Científico e Tecnológico

FAPEMIG: Fundação de Amparo à Pesquisa de Minas Gerais

FINEP: Financiadora de Estudos e Projetos

LMIC: low- and middle-income countries

mHealth: mobile health

TeleHAS: tele-hipertensão arterial sistêmica (arterial hypertension system)

\author{
Edited by G Eysenbach; submitted 18.01.18; peer-reviewed by H Singh, P Devarsetty, C Bonner, J Sussman; comments to author \\ 11.07.18; revised version received 05.11.18; accepted 10.12.18; published 25.03.19 \\ Please cite as: \\ Silveira DV, Marcolino MS, Machado EL, Ferreira CG, Alkmim MBM, Resende ES, Carvalho BC, Antunes AP, Ribeiro ALP \\ Development and Evaluation of a Mobile Decision Support System for Hypertension Management in the Primary Care Setting in \\ Brazil: Mixed-Methods Field Study on Usability, Feasibility, and Utility \\ JMIR Mhealth Uhealth 2019;7(3):e9869 \\ URL: http://mhealth.jmir.org/2019/3/e9869/ \\ doi: $\underline{10.2196 / \text { mhealth. } 9869}$ \\ PMID: 30907740
}

CDaniel Vitório Silveira, Milena Soriano Marcolino, Elaine Leandro Machado, Camila Gonçalves Ferreira, Maria Beatriz Moreira Alkmim, Elmiro Santos Resende, Bárbara Couto Carvalho, André Pires Antunes, Antonio Luiz Pinho Ribeiro. Originally published in JMIR Mhealth and Uhealth (http://mhealth.jmir.org), 25.03.2019. This is an open-access article distributed under the terms of the Creative Commons Attribution License (https://creativecommons.org/licenses/by/4.0/), which permits unrestricted use, distribution, and reproduction in any medium, provided the original work, first published in JMIR mhealth and uhealth, is properly cited. The complete bibliographic information, a link to the original publication on http://mhealth.jmir.org/, as well as this copyright and license information must be included. 